\title{
Corpos femininos ocupados e a dupla resistência ao colonialismo e ao patriarcado
}

\author{
Occupied female bodies and the double resistance to colonialism and patriarchy
}

Cuerpos femeninos ocupados y la doble resistencia al colonialismo y al patriarcado

Ashjan Sadique Adi ${ }^{1}$

Soraya Misleh ${ }^{2}$

Muna Muhammad Odeh ${ }^{3}$

\section{Resumo:}

A luta do povo palestino pela libertação nacional está articulada em um processo histórico, socioeconômico e eminentemente político dentro do qual o Movimento das Mulheres Palestinas tem evoluído nos últimos 100 anos, trazendo à tona as tensões e contradições do sistema patriarcal e seu papel em atrasar a construção de uma agenda feminista anticolonial. Os movimentos de mulheres palestinas avançaram em uma série de demandas socioculturais e políticas, incluindo autonomia econômica, direitos de herança, violência de gênero denotando altos níveis de iniciativa e resiliência. Referências explicativas sobre a condição das mulheres palestinas, sempre retratadas com a ocupação militar israelense como pano de fundo onde se discute a conclusão da libertação nacional e, por outro, a urgência de enfrentar as expressões de desigualdade de gênero cuja manifestação mais persistente se encontra na violência contra as mulheres nos domínios público e privado.

Palavras-chave: Movimento de Mulheres Palestinas, Luta anti Colonial, Ocupação Israelense, Violência de gênero, Resistência e Resiliência na Palestina.

\begin{abstract}
:
The struggle of the Palestinian people for national liberation is articulated in a historical, socioeconomic and eminently political process within which the Palestinian Women's Movement has evolved over the last 100 years, bringing to light the tensions and contradictions of the patriarchal system and its role in delaying the construction of a feminist anti-colonial agenda. The Palestinian women's movements have advanced a range of socio-cultural and political demands including economic autonomy, inheritance rights gender violence denotating high levels of initiative and resilience. Explanatory references about the condition of Palestinian women, always portrayed with the Israeli military occupation as a background where the conclusion of national liberation is in

\footnotetext{
${ }^{1}$ Graduada em Psicologia e mestra em Educação pela UFMS (Universidade Federal de Mato Grosso do Sul), doutoranda em Psicologia Social pela USP (Universidade de São Paulo), membra do GRACIAS (Grupo de Antropologia em Contextos Árabes e Islâmicos) e diretora da FEPAL (Federação Árabe-Palestina do Brasil).

2 Jornalista palestino-brasileira, mestre e doutoranda em Estudos Árabes pela Universidade de São Paulo, autora do livro "Al Nakba - Um estudo sobre a catástrofe palestina”. (São Paulo: Editora Sundermann, 2017) e de diversos artigos sobre o tema.

${ }^{3}$ Palestina, bióloga e Professora Associada de Saúde Coletiva na Faculdade de Ciências da Saúde da Universidade de Brasília - UNB.
} 
dispute, and on the other, the urgency of facing expressions of inequity of gender whose most persistent manifestation is found in violence against women in the public and private domains.

Key Words: Palestinian Women's Movement, Anti-Colonial Struggle, Israeli Occupation, Gender Violence, Resistance and Resilience in Palestine.

Resumen: La lucha del pueblo palestino por la liberación nacional se articula en un proceso histórico, socioeconómico y eminentemente político dentro del cual el Movimiento de Mujeres Palestinas ha evolucionado durante los últimos 100 años, sacando a la luz las tensiones y contradicciones del sistema patriarcal y su papel. en retrasar la construcción de una agenda feminista anticolonial. Los movimientos de mujeres palestinas han presentado una serie de demandas socioculturales y políticas que incluyen autonomía económica, derechos de herencia, violencia de género que denotan altos niveles de iniciativa y resiliencia. Referencias explicativas sobre la condición de la mujer palestina, retratada siempre con la ocupación militar israelí como trasfondo donde se disputa la conclusión de la liberación nacional, y por otro, la urgencia de enfrentar expresiones de inequidad de género cuya manifestación más persistente se encuentra en violencia contra la mujer en el ámbito público y privado.

Palabras Clave: Movimiento de Mujeres Palestinas, Lucha Anticolonial, Ocupación Israelí, Violencia de Género, Resistencia y Resiliencia en Palestina.

\section{Mais de 100 anos de colonização e resistência das mulheres palestinas}

Embora a Nakba, catástrofe com a autoproclamação do Estado de Israel em 15 de maio de 1948 mediante limpeza étnica planejada ${ }^{4}$, seja geralmente identificada a partir desse momento, ela teve início muito tempo antes. E continua até os dias atuais. Historiadores palestinos têm apontado que já são mais de 100 anos de uma das maiores injustiças da era contemporânea. ${ }^{5}$ Os marcos históricos desse processo são acompanhados da resistência palestina e, assim, do protagonismo feminino.

O primeiro deles se dá ao surgimento do sionismo político moderno, em fins do século XIX, cujo fundador é o jornalista judeu, nascido na Hungria, Theodor Herzl (1860-1904). Em 1896, ele publica "O Estado judeu” em que vincula a chamada "questão judaica" não à religião ou a aspecto social, mas a um problema nacional. ${ }^{6}$ Ou seja, deveriam constituir seu próprio Estado para se livrarem do "antissemitismo" na Europa do Leste e Central. No ano seguinte, ocorre o I Congresso Sionista na Basileia, Suíça, com a participação de 200 delegados. A Palestina é então escolhida como o local para essa colonização:

\footnotetext{
${ }^{4}$ Soraya Misleh. Al Nakba - Um estudo sobre a catástrofe palestina (São Paulo: Editora Sundermann, 2017), 19-20.

${ }^{5}$ Rashid Khalidi. The Hundred Years' War on Palestine: A History of Settler Colonial Conquest and Resistance (New York: Metropolitan Books, 2020).

${ }^{6}$ Soraya Misleh. Al Nakba - Um estudo sobre a catástrofe palestina (São Paulo: Editora Sundermann, 2017), 22-27.
} 
Esse nome por si só seria um toque de reunir poderosamente empolgante para o nosso povo (...) Para a Europa, constituíriamos aí um pedaço de fortaleza contra a Ásia, seríamos a sentinela avançada da civilização contra a barbárie. Ficaríamos como Estado neutro, em relações constantes com toda a Europa, que deveria garantir nossa existência. ${ }^{7}$

O conteúdo orientalista - de um "Oriente" atrasado e bárbaro inventado ante um "Ocidente" racional e civilizado ${ }^{8}$, em que o "Estado de Israel" se identifica com este último - serve ao projeto colonial. É preciso desumanizar o “outro”. A Palestina à época contava não mais que 6\% de judeus. Assim, desde seus primórdios, o sionismo político moderno tinha ciência de que seria preciso o que denominavam "transferência populacional”, como fica evidenciado nos diários de suas lideranças à época - um eufemismo para limpeza étnica, de modo a mudar a demografia e então constituir um "Estado judeu". 9

As mulheres são as primeiras a se darem conta dessa ameaça. Já em fins do século XIX, quando se iniciam as ondas de imigração sionista à Palestina para a "conquista da terra e do trabalho", elas revelam o protagonismo que acompanhará a história, ao se levantarem contra a colonização. ${ }^{10}$

Mas é no segundo marco desse processo que sua atuação ganha proeminência. Este se dá ao final da Primeira Guerra Mundial (1914-1918) e em meio à iminente derrota do Império TurcoOtomano após quase 400 anos de dominação do Oriente Médio e Norte da África. Como "espólios" de guerra, os aliados europeus, já em 1916, haviam dividido a região em áreas de influência. A GrãBretanha ficaria com o mandato sobre a Palestina e em 2 de novembro de 1917, emite a chamada “Declaração Balfour”, na qual afirma ser favorável à constituição de um lar nacional judeu em terras palestinas.

Até então, em nível organizacional, as mulheres estavam mais concentradas em associações e sociedades de ajuda humanitária, preocupadas em especial em garantir educação para meninas e mulheres. Após a Declaração Balfour, emergem movimentos nacionalistas e, em aliança, organizações de mulheres que vão sedimentar o caminho ao feminismo anticolonial - que considera inseparável a luta pela emancipação das mulheres e pela libertação nacional.

\footnotetext{
${ }^{7}$ Theodor Herzl. O Estado judeu. Tradução David José Pérez. (Rio de Janeiro: Garamond, 1998), 66.

${ }^{8}$ Edward Said. Orientalismo: O Oriente como invenção do Ocidente. Tradução Rosaura Eichenberg (São Paulo: Companhia das Letras, 2007), 29-31.

${ }^{9}$ Nur Masalha. O conceito de "transferência" no pensamento político sionista - 1882-1948. Tradução Leo Misleh e Teresa Bosco Ferreira (São Paulo: Editora Sundermann/Monitor do Oriente, 2021), 17-19.

10 Dima Samaroo. "The Political Participation of Palestinian Women in Official and Non-Official Organizations in Limited Horizon", Kings' College London, Department of War Studies, International Centre for the Study of Radicalisation, 2018, 10. Disponível em: https://icsr.info/wp-content/uploads/2018/12/KPMED-Paper_The-PoliticalParticipation-of-Palestinian-Women-in-Official-and-Non-Official-Organizations-in-Limited-Horizon-1.pdf. Acesso em: 25 de outubro de 2021.
} 
Os anos 1920 são marcados por sua emergência nas mais distintas cidades palestinas. Em agosto de 1929 acontece a revolta de al-Buraq, após provocação sionista que desafiava o controle muçulmano sobre o que é hoje denominado Muro Ocidental em Jerusalém. Aos protestos, somam-se mulheres, que ao final são nove das cerca de 120 vítimas fatais palestinas. Segundo escreve uma das participantes Matiel Mogannam, que está entre as pioneiras do movimento, esse acontecimento representa a ruptura da "passividade feminina" - baseada na tradição. Por "força das circunstâncias", elas são empurradas à ação. ${ }^{11}$

Assim, em 26 de outubro de 1929, ocorre o I Congresso de Mulheres Árabes em Jerusalém, com a presença de 200 delegadas, cristãs e muçulmanas de várias cidades palestinas e aldeias maiores. A maioria integrava a elite e era, contudo, esposa de notáveis ou lideranças do movimento nacionalista. Não obstante, a historiadora Ellen Fleischmann considera equivocado dizer que sua organização funcionava como mero apêndice, embora houvesse "certo grau de cooperação". ${ }^{12}$

O Congresso elege o Comitê Executivo de Mulheres Árabes, com 14 integrantes, e aprova resoluções como as que exigiam o fim da imigração colonial sionista e o fim da Declaração Balfour. Ao fim do evento, as participantes saem em carreata que reuniu 120 veículos, com paradas em frente à sede do mandato britânico e consulados estrangeiros. Esse é a pedra basilar ao surgimento de diversas organizações e comitês populares de mulheres nas áreas urbanas. ${ }^{13}$

O terceiro marco é a revolução de 1936-1939 na Palestina. A colonização sionista se intensifica, sob o guarda-chuva do mandato britânico. Como consequências, expulsão de camponeses de suas terras, desemprego, carestia, fome e pobreza. Detonador ainda é o assassinado do revolucionário sírio Izz el-Dim ao-Qassam, em combate contra os sionistas na Palestina, no mês de novembro de $1935 .{ }^{14}$

Essa situação é o caldo para a revolução contra o mandato britânico e a colonização sionista que se inicia com greve geral palestina em abril de 1936 e empurra o Alto Comissariado Árabe a chamar o levante. ${ }^{15}$ É o momento em que camponeses e trabalhadores entram no movimento, incluindo mulheres. Estas atuavam em diversas frentes: cuidavam dos feridos, alertavam para a chegada dos sionistas e britânicos, garantiam suprimentos e alimentação aos combatentes e também

\footnotetext{
${ }^{11}$ Matiel Mogannam, The Arab Women and The Palestine Problem (London: Herbert Joseph Ltd, 1937, digitalizado pela Birzeit University Library), 67.

12 Ellen Fleischmann. “The Emergence of the Palestinian Women's Movement, 1929-39”, Journal of Palestine Studies, April 2000, 20-21. Disponível em: http:www.palestine-studies.org/ps/fulltext/40801. Acesso em: 25 de outubro de 2021. 13 Ibidem, 19.

${ }^{14}$ Ghassan Kanafani. A revolta de 1936-1939 na Palestina. Tradução Guilherme Rodrigues e Fabio Bosco (São Paulo: Editora Sundermann, 2015), 67-70.

15 Ibidem.
} 
atuavam nas linhas de batalha, em brigadas femininas ou mistas comandadas por mulheres. ${ }^{16} \mathrm{~A}$ revolução é derrotada ao final: são mais de 5 mil mortos e 14 mil feridos. ${ }^{17}$ Os palestinos se encontravam absolutamente vulneráveis, enquanto as paramilícias sionistas eram fortemente armadas pela Europa.

A derrota, assim, pavimenta o caminho para a pedra fundamental da Nakba, em 1948, o quarto marco histórico da limpeza étnica planejada. O sinal verde foi dado pela recém-criada Organização das Nações Unidas (ONU), cuja Assembleia Geral recomendou em 29 de novembro de 1947 a partilha da Palestina em um estado judeu e um árabe, com Jerusalém sob administração internacional. ${ }^{18}$ Em fevereiro do mesmo ano, as irmãs Nariman e Moheeba Khoorshed, que eram educadoras, fundam a brigada armada feminina Al Zahrat al Uqhuwan (Flores do crisântemo), precedendo outras que viriam a travar luta desesperada na tentativa de impedir a catástrofe. ${ }^{19}$

Ao final, os sionistas ocuparam $78 \%$ da Palestina histórica, avançando inclusive para o que recomendava a Assembleia Geral da ONU - 55\% para o estado judeu e 45\% para o árabe. Oitocentos mil palestinos foram expulsos violentamente e o estupro foi utilizado como arma para o despovoamento de $2 / 3$ da sociedade, que teve cerca de 500 de suas aldeias destruídas. A Palestina foi radicalmente transformada. ${ }^{20}$

Internamente, a educadora Hind al-Husseini (1916-1994) constituiu um orfanato para abrigar das crianças que perderam suas famílias, iniciativa que teve início quando avistou 55 delas cujos pais foram vítimas do genocídio na pequena aldeia de Deir Yassin, em Jerusalém, no dia 9 de abril de 1948. Em seis meses seu orfanato contava cerca de 2 mil. $^{21}$

No refúgio, as mulheres iniciaram organizações de ajuda humanitária e algumas poucas foram proeminentes no emergente movimento de libertação nacional a partir dos anos 1960, que culminou na criação da Organização para a Libertação da Palestina (OLP) em maio de 1964. No ano seguinte, surge, atrelada a esta, a União Geral das Mulheres Palestinas.

\footnotetext{
${ }^{16}$ Faiha Abdulhadi. The Political Role of Palestinian Woman in the 1930s. Translated from the Arabic Language by Nitham Sais (Ramallah: The Palestinian Women’s Research \& Documentation Center, 2015), 32.

${ }^{17}$ Ghassan Kanafani. A revolta de 1936-1939 na Palestina. Tradução Guilherme Rodrigues e Fabio Bosco (São Paulo: Editora Sundermann, 2015), 100.

18 Ver Resolução 181, de 29 de novembro de 1947, da Assembleia Geral das Nações Unidas. Disponível em: https://unispal.un.org/dpa/dpr/unispal.nsf/0/7f0af2bd897689b785256c330061d253. Acesso em: 25 de outubro de 2021.

${ }^{19}$ Mervat Sadiq. "The Palestinian "Chysantemun"... A secret feminist organization before the Nakba", Al Jazeera, 15 de maio de 2021 (tradução nossa). Disponível em árabe: https://bit.ly/3hOn0ks. Acesso em: 25 de outubro de 2021.

${ }^{20}$ Soraya Misleh. Al Nakba - Um estudo sobre a catástrofe palestina (São Paulo: Editora Sundermann: 2017), 64-54.

21 Hind al-Husseini - Personal Info. Disponível no portal Visit Palestine: http://visitpalestine.ps/palestinianpersonalities/hind-al-husseini/. Acesso em: 25 de outubro de 2021.
} 
Dois anos depois, entre 5 e 10 de junho de 1967, o quinto marco da Nakba, desta vez sob a denominação Naksa (revés): a ocupação militar sionista das terras palestinas remanescentes em 1967, ou seja, Jerusalém Oriental, Gaza e Cisjordânia. Ao final da década e início dos anos 1970, o protagonismo feminino alcança outro patamar, inclusive com participação em ações diretas, como sequestros de aviões. Entre as mulheres que se envolveram nessas iniciativas, Leila Khaled (1944-), Therese Halasa (1954-2020) e Rima Tannous (1952-). Estas últimas participaram do sequestro em 9 de maio de 1972 do avião belga Sabena (voo 571), na rota para Tel-Aviv, visando a troca dos passageiros por 315 prisioneiros políticos palestinos. Foram detidas na ação, torturadas e condenadas à pena perpétua. No entanto, foram libertadas respectivamente em 1979 e 1983 em troca de prisioneiros. No cárcere, atuavam na educação de meninas e mulheres, bem como buscavam manter vivo o espírito coletivo de resistência. ${ }^{22}$

Segundo Misleh $(2020)^{23}$, o mais recente movimento feminista de mulheres palestinas o Tal’at, criado em 2019, organizou uma ação mundial (nos territórios palestinos ocupados em 1948 e 1967, no exílio, nos países árabes e na Europa) articulada em protesto ao feminicídio praticado na sociedade palestina ocupada conclamando um feminismo anticolonial como condição para a libertação do povo palestino:

Sem poderem se encontrar em sua própria terra, diante do apartheid israelense, extrapolaram as fronteiras coloniais, a partir do chamado: "Palestina livre, mulheres livres" e "Não há honra no assassinato." A ação, articulada pelo recém-criado movimento feminista palestino Tal'at, se deu a partir de agosto de 2019, em protesto pelo assassinato da jovem Israa Ghrayeb por familiares. Aos 21 anos de idade, ela é uma das dezenas de vítimas de feminicídio em sua terra ocupada por Israel no ano - os números variam de 18 a 34, a depender das fontes pesquisadas. 24

Aqui vale ressaltar os argumentos de duas jovens, integrantes do movimento Tal'at - Hala Marshood e Riya Alsanah; em artigo de sua autoria publicado em fevereiro último no site da associação Europe Solidaire Sans Frontières, citadas pela Misleh (2020) onde se debruçam sobre o enfrentamento de estereótipos coloniais relativos a mulheres palestinas e árabes de um modo geral:

Desafiando os estereótipos racistas e orientalistas, as mulheres do Oriente Médio e da região do Norte da África estão na vanguarda da luta pela construção de uma sociedade mais justa e igualitária. Enquanto escrevemos, as mulheres estão ocupando praças e marchando pelas ruas do Iraque devastado pela guerra, determinadas a desempenhar um papel ativo na definição de seu futuro. No Líbano, as mulheres não saíram das ruas, quebrando bancos, agitando pelos direitos dos refugiados sírios e palestinos e nos dando educação em tempo

\footnotetext{
${ }^{22}$ PLO Unified Information, Foreign Information Department. Palestinian Political Prisoners: Struggle Behind Iron Bars, Beirute, 1979, 71-81.

${ }^{23}$ Soraya Misleh, "Palestina livre, mulheres livres".

${ }^{24}$ Ibid.
} 
real do feminismo revolucionário na prática. Feministas em todo o mundo estão incorporando e articulando movimento que vê a opressão sistemática e estruturalmente enraizada no capitalismo, cruzando-se com raça, sexualidade, colonialismo e ambientalismo. Em suma, um feminismo que vai além das demandas baseadas no gênero individual, instando-nos a lutar por um mundo mais justo e equitativo para todos. Tal'at faz parte dessa tradição feminista revolucionária. ${ }^{25}$

A Nakba continua, e as jovens que hoje são vanguarda na resistência seguem a se inspirar nas muitas mulheres invisibilizadas na história que as antecederam. Este é seu legado. Seus traumas silenciados e suas vozes abafadas ecoam nos gestos de uma nova geração que se recusa a ser apagada do mapa.

\section{Um olhar psicológico sobre a violação de corpos femininos palestinos}

A perspectiva teórica que fundamenta este item do artigo trata-se da Psicologia Social. Esta tem como foco os efeitos das desigualdades estruturais e do contexto sócio-político-econômico vigente na psique e na subjetividade individual e coletiva, refletindo e promovendo mudanças políticas, prevenção e ação social que desafiem o status quo, expondo suas contradições e fortalecendo grupos historicamente marginalizados.

Versaremos, aqui, a respeito da violência colonial e patriarcal contra as mulheres palestinas e suas consequências psicológicas, assim como, seus mecanismos de resistência e de resiliência contra esses processos nos espaços privados, já que nos espaços públicos isso já foi apresentado anteriormente. Nosso objetivo, portanto, é trazer um apanhado de estudos voltados a esta temática, focando em alguns de seus resultados.

Consoante Hammad e Tribe (2020), há uma escassez de pesquisas em nível internacional que investigam o impacto psicológico da violência estrutural, da opressão econômica, do bloqueio militar, do controle de recursos, da pobreza, da restrição de liberdade e de oportunidades de subsistência decorrentes da violência política contra mulheres no contexto da Palestina ou como também são denominados, nos Territórios Palestinos Ocupados - TPO's. No âmbito nacional, igualmente. E ademais, observamos poucos estudos a respeito da violência de gênero contra mulheres palestinas, a respeito de suas organizações sociais e movimentos políticos contra esse fenômeno, assim como um olhar da Psicologia sobre o mesmo. Consideramos que se a história da Palestina é uma história silenciada, a história das mulheres palestinas é ainda mais. Em razão disso, decidimos escrever sobre

\footnotetext{
25 Ibid.
} 
este último tema, considerando a relevância social e científica deste para o espaço acadêmico brasileiro. ${ }^{26}$

As mulheres palestinas, assim como as mulheres de diferentes regiões do mundo e seu regime capitalista-patriarcal, estão sujeitas a diversas violências de gênero, sejam físicas, psicológicas, sexuais, seja pelo patriarcado, seja pelo colonialismo, seja no âmbito privado, seja no âmbito público, seja por soldados, seja por companheiros e por próprios familiares, seja contra seus corpos, suas casas, seus filhos, suas terras.

No contexto de colonização, a lógica da violência colonial (especificamente sexual) se fundamenta na ideologia de que os corpos nativos são inerentemente violáveis e, por extensão, as terras nativas também. ${ }^{27} \mathrm{O}$ que nos permite inferir que o objetivo do projeto sionista de dominação e colonização de terras palestinas é inseparável do projeto de dominação e colonização dos corpos palestinos, em especial, dos corpos das mulheres, por sua fertilidade e capacidade reprodutiva.

A partir da constatação de um sofrimento psicológico e social contínuo aliado a um dos mais baixos índices de qualidade de vida do mundo ${ }^{28}$, causado pela ocupação militar israelense, e a conjuntura de conflito prolongado, que impacta negativamente a capacidade do indivíduo de suprir necessidades básicas e cruciais como água potável, eletricidade, educação, saúde e emprego, problematizamos a insuficiência epistemológica da individualização, da medicalização e a despolitização da angústia palestina, e a necessidade de ir além dos modelos convencionais de definição e de nosologia de transtornos psíquicos que, por serem descontextualizados e buscarem uma padronização supostamente universal, nem sempre são capazes de atender às especificidades dos adoecimentos psíquicos numa conjuntura de apartheid, colonialismo e genocídio, a exemplo do transtorno de stress pós-traumático e sua inadequação num contexto de traumas reincidentes e permanentes. $^{29}$

Nesta perspectiva psicossociológica, consideramos que a compreensão e promoção da saúde mental e do bem-estar psíquico não podem estar apartadas da compreensão e superação dos problemas presentes no contexto social e político mais amplo, relativos ao acesso à liberdade, à segurança, à justiça, aos direitos humanos, na linha do que sustentam psicólogos como Kagan et al.

\footnotetext{
26 Jeyda Hammad and Rachel Tribe, "Social suffering and the psychological impact of structural violence and economic oppression in an ongoing conflict setting."

27 Andrea Smith, "Not an indian tradition: the sexual colonization of native peoples".

${ }^{28}$ Mataria et al., "The quality of life of Palestinians living in chronic conflict"

${ }^{29}$ Giacaman et al., "Quality of life"
} 
$(2011)^{30}$ e Martín-Baró (1994) ${ }^{31}$. Ademais, concordamos com as diretrizes do Comitê Permanente Interagências (2007), para as quais a promoção dos direitos humanos anda de mãos dadas com a promoção da saúde mental.

\section{Corpos femininos palestinos: historicamente sob dupla ocupação}

Shahd Wadi (2009), descendente de palestinos e pesquisadora de Estudos Feministas pela Universidade de Coimbra, argumenta que Israel procura utilizar os corpos femininos para controlar o povo palestino como um todo, atrelando opressões de gênero para fins políticos mais amplos. Ou seja, ocupa-se a terra no sentido nacional e macropolítico e "ocupa-se" a mulher no sentido pessoal, micropolítico, ocupações que se articulam e se reforçam. É neste sentido que segue contundente a afirmação de que a Palestina só será libertada com a libertação de suas mulheres, estas lutas seguem juntas. ${ }^{32}$

E conforme a autora, a função reprodutiva da mulher palestina é central no conflito, fazendo parte da luta nacional. Algumas mulheres vão dizer: "Temos um ventre militar e damos luz a combatentes". Existe assim, um orgulho em participar da resistência, mas ao mesmo tempo um sentimento de resignação por participar desta luta de modo restrito ao âmbito biológico, enquanto um útero militar e aceitando este quase exclusivo papel, que é outra forma de objetificação desse corpo feminino num contexto de resistência.

Ademais, na narrativa israelense, a relação entre os dois lados desse contexto de ocupação é representada por uma relação homem/mulher, sendo a Palestina, a mulher e Israel, o homem. Noutras palavras, o colonizador é o patriarca, a Palestina, a noiva rebelde e a resistência de seu povo, o dote. ${ }^{33}$ O que podemos metaforizar como uma "união" forçada e indesejada pela mulher, sem seu consentimento, uma relação permeada por abusos; uma relação de estupro, como historicamente ocorreu com mulheres indígenas e negras no Brasil e o colonizador branco-europeu.

De todo modo, a fetichização da fertilidade tornou as mulheres palestinas alvos da retórica nacionalista que politiza significativamente sua reprodução. Para os sionistas, as mulheres palestinas sempre foram, e continuam sendo, os principais corpos alvejados pela limpeza étnica; a principal peça de sua máquina genocida. ${ }^{34}$

\footnotetext{
${ }^{30}$ Kagan et al., "Critical community psychology".

31 Martín-Baró, "Writings for a liberation psychology".

32 Shahd Wadi, "Feminismos".

${ }^{34}$ Shalhoub-Kevorkian et al., "Sexual violence"
} 
Segundo as autoras supracitadas, estudos apontam que o estado sionista mobiliza a violência contra os corpos e a sexualidade das mulheres palestinas, através do abuso sexual militarizado, para fortalecer as estruturas patriarcais, o que por consequência, contribui para a expulsão dos palestinos de suas terras. Sendo assim, o estado israelense e as forças militares exploram a ameaça de violência sexual contra as mulheres palestinas e as culturais concepções patriarcais de sexualidade e "honra" para "recrutar palestinos como colaboradores" durante os períodos de levantes e impedir tentativas de resistência organizada, tornando, portanto, o estupro uma arma de guerra.

\section{Os impactos psíquicos da violência doméstica}

Apresentado brevemente este contexto, traremos agora alguns apontamentos sobre as consequências psíquicas da violência. Iniciaremos com a violência doméstica.

Conforme Thabet, Abu Tawahina e El Sarraj (2007), mulheres palestinas que sofrem abusos físicos e psicológicos, tendem a apresentar como principais consequências psicológicas sobre sua saúde mental sintomas de ansiedade, depressão e TEPT - Transtorno de Stress Pós-Traumático, sendo que os dois primeiros atingem os níveis moderado a grave. Tais resultados revelam uma proeminente necessidade de mais projetos de atendimento psicoterapêutico voltado para este público, assim como a inclusão de programas que visem desenvolver e aprimorar as estratégias de enfrentamento destas circunstâncias por parte das mulheres.

Mulheres que foram vítimas de violência física, além de vivenciar a curto, médio e longo prazo os efeitos das lesões, são mais propensas a sofrer uma variedade de problemas de saúde, incluindo abuso de drogas, transtornos alimentares e distúrbios sexuais, ginecológicos e gastrointestinais. (Fleming, Mullen, Sibthorpe, \& Bammer, 1999).

A respeito dos tipos de violência doméstica, os resultados mostraram que os tipos de agressão mais comuns nas mulheres palestinas foram insultos, xingamentos e gritos. A maioria dos casos de violência são infligidos por parceiros ou ex-parceiros. Resultados apontam também que a violência doméstica na Palestina é menos incidente do que nos países ocidentais, de um modo geral, o que pode estar relacionado à proteção da família extensa.

Segundo estudo de Thabet, Abu Tawahina e El Sarraj (2007), as mulheres que vivem sozinhas em família nuclear tiveram melhores condições de negociar as situações de violência doméstica do que as que vivem em famílias extensas. Ademais, não foram constatadas diferenças significativas entre o tipo de residência, o nível educacional das mulheres, a renda mensal e a violência infligida. 
Isto demonstra que tal fenômeno ultrapassa as questões de classe, reforçando que se trata de um problema estrutural, embora seja preciso reconhecer que em termos de recursos financeiros, mulheres pertencentes a classes mais abastadas tenham condições mais privilegiadas para enfrentar estas situações. ${ }^{35}$

\section{Os impactos psíquicos da violência colonial}

Pesquisas revelam que a despeito das expectativas de gênero projetadas, parece haver pouca diferença entre os impactos psíquicos da violência colonial para mulheres e homens no que concerne a sensações, preocupações e sentimentos, sejam cotidianos e/ou existenciais. Por isso, abordaremos neste item, impactos psíquicos sem distinções de gênero específicas, haja vista afetarem ambos de forma semelhante. (Hammad e Tribe, 2020). ${ }^{36}$

De acordo com os estudos de Barber et al. (2014) $)^{37}$ e de Hamad e Pavanello (2012) ${ }^{38}$, ser militarmente ocupado significa ser politicamente controlado, uma situação que gera tensão psicológica, sentimentos de medo, de insegurança contínua, de humilhação (sendo esta última considerada um trauma invisível da guerra) ${ }^{39}$, de frustração e de desespero; preocupações com a possibilidade de ser preso e de sofrer invasões, bombardeios, tiroteios.

Outros sentimentos comuns constatados são os de violação e perda da dignidade, a exemplo de "não viver como humanos", de viver uma morte lenta, uma existência insuportável, uma sensação de que a vida está suspensa, em espera, de não ser capaz de continuar, de não poder planejar o futuro e a falta de realização pessoal, sobretudo por cidadãos da Faixa de Gaza, que também relatam sentimentos de viver em uma "grande prisão" ${ }^{40}$, simbolizando sentimentos de punição e aprisionamento, ${ }^{41}$ que fazem jus à consideração de que a Faixa de Gaza é "uma prisão a céu aberto" e de que o bloqueio militar é uma 'punição coletiva', segundo o Direito Internacional ${ }^{42}$.

Além do mais, tais achados reforçam o crescente reconhecimento de que a insegurança humana, as restrições econômicas, o desemprego e a pobreza crônicas geram mais angústia e ameaça ao bem-estar do que a exposição direta à violência em contextos de guerra ou conflito, sendo que as

\footnotetext{
35 Thabet, "Effect of Domestic Violence".

${ }^{36}$ Hammad, Jeyda and Rachel Tribe, "Social suffering".

37 Barber et al., "Politics drives human".

${ }^{38}$ Hamad and Pavanello, "Transforming cash transfers".

${ }^{39}$ Giacaman et al., "Humiliation".

${ }^{40}$ A. Thabet and S. Thabet, "Stress, trauma"

41 A. Bseiso and A. Thabet, "The relationship", 499.

42 Amnesty International, "The state of the world's human rights", 207.
} 
primeiras acentuam os traumas da segunda. ${ }^{43}$ Neste sentido, a opressão contínua, sistêmica e estrutural é potencialmente mais psicologicamente prejudicial que incidentes específicos de violência.

Seguindo a linha de argumentação de Bulhan $(1985)^{44}$, a violência não se reduz ao emprego direto da força física; a opressão em ambientes de conflito raramente consiste na atuação isolada da força física, existe, sim, um complexo sistema de opressão social, étnica, econômica, compondo uma violência estrutural, que, por sua vez, é considerada a forma mais letal desta por ser mais difícil de discernir, de identificar, pois se apresenta como uma ordem de vida rotineira. ${ }^{45}$

Evidências de pesquisas recentes também identificaram uma forma existencial única de sofrimento mental entre os palestinos: o sentimento de que o espírito, a moral, a vida e/ou o futuro foram quebrados ou destruídos. ${ }^{46}$

\section{Violência colonial contra mulheres no ambiente doméstico e suas resistências}

Um alvo central da violência política contemporânea é a casa, o lar, que está regularmente sujeito a vigilâncias, invasões e repetidas ameaças ou demolições reais. ${ }^{47}$ A violação ou destruição dos ambientes domésticos das mulheres provocam medo, ansiedade, tristeza, humilhação e desamparo, mas também, processos de resistência prática e emocional para proteger seus filhos e garantir a sobrevivência econômica, familiar e cultural. ${ }^{48}$

O argumento do sociólogo e médico, Aaron Antonovsky $(1987)^{49}$, de que o bem-estar em meio a adversidades depende do senso de coerência de uma pessoa, que por sua vez está voltada às múltiplas maneiras que a casa e sua materialidade apoiam as necessidades humanas de constância e previsibilidade.$^{50}$ Por seu turno, Giddens (1990), se referiu ao sentido de compreensão e de confiança no mundo como segurança ontológica: "a confiança que a maioria dos seres humanos tem na continuidade de sua identidade e na constância do ambiente social, material e de ação". ${ }^{51}$

\footnotetext{
43 Barber et al., "Politics drives human"

44 Bulhan, Frantz Fanon and the psychology of oppression.

45 Ibid.

46 Ibid.

${ }^{47}$ Brickell, "Geopolitics of home."

48 Cindy A. Sousa, Susan Kemp, and Mona El-Zuhairi. "Dwelling within political"

${ }^{49}$ Antonovsky, Unraveling the Mystery of Health.

50 Young,"House and home"

${ }^{51}$ Giddens, The Consequences of Modernity, 92.
} 
A confiança presente no dia-a-dia, nas pessoas e no seu ambiente fornece estabilidade e segurança, essencial não só para o bem-estar, mas também para a identidade pessoal e coletiva. ${ }^{52}$ Confirmando a afirmação de Seamon $(1979)^{53}$ que "a pessoa que está em casa ocupa um espaço sobre o qual ela está no comando", o controle, portanto, surge como um tema central em uma gama de estudos empíricos que exploram as conexões entre casa, segurança ontológica e saúde. ${ }^{54}$

Além disso, pesquisas com mulheres sobre as experiências domésticas de violência política, muitas vezes, destacam a importância que estas atribuem ao seu papel maternal. ${ }^{55}$ Sendo assim, interrupções nestes ambientes podem ser entendidos como ataques profundos à autonomia das mulheres e ao sentido de maternidade, particularmente porque prejudicam as tarefas do cuidar. ${ }^{56}$

\section{Palestina: espaço-cídio e solastalgia}

A violência política na Palestina ameaça noções convencionais de casa como um refúgio seguro e espaço de autonomia. Neste contexto, as fronteiras entre o espaço público e privado são sempre porosas ${ }^{57}$, pois os arranjos políticos penetram os ambientes domésticos diretamente, como em invasões e demolições, e indiretamente, através dos desafios de viver em insegurança espacial crônica.

Por sua vez, destruições de casas palestinas facilitam a expropriação israelense das terras, transferindo a população palestina ${ }^{58}$, um processo que Hanafi (2009) ${ }^{59}$ denominou de espaço-cídio, segundo a qual: "No conflito palestino-israelense, o alvo é o lugar", consistindo numa estratégia que ameaça a contiguidade geográfica, a 'pátria' coletiva e, por consequência, o bem-estar dos palestinos, cerceados em atividades básicas como ir para casa ou visitar amigos”. Neste sentido, a violência ao lar não afeta apenas o âmbito familiar, significa igualmente ameaças a uma pátria ${ }^{60}$ compartilhada $^{61}$.

$\mathrm{Na}$ linha das discussões sobre "Habitar em contexto de guerra"62, a angústia peculiar de viver em um ambiente que não proporciona bem-estar, segurança e exercício da individualidade foi

\footnotetext{
52 Kearns et al., "'Beyond four walls"”

53 Seamon, A Geography of the Life-world, 80.

54 Padgett, "There's no place like (a) home"

${ }^{55}$ Ward, "Women of the Lebanese mountains"

56 Akesson, "Castle and cage"

${ }^{57}$ Massey, Space, Place, and Gender

${ }^{58}$ Falah, "War, peace and land"

59 Hanafi, "Spacio-cide", 109.

60 Ibid.

61 Falah, "War, peace and land"

62 Brickell, "Geopolitics of home."
} 
conceituada por Albrecht e seu colegas como solastalgia: "a saudade da noção de casa que se sente mesmo estando no próprio ambiente doméstico" (Albrecht, 2012, p. 227), ou a angústia de ser incapaz de obter conforto (para si mesmo) e promover o bem-estar (aos outros) dentro de sua própria casa, de seu próprio ambiente. ${ }^{63}$

Diante destas considerações, estudos revelam que preocupações em estar constantemente vigiadas foram particularmente significativas entre mulheres que apontaram que mesmo se os soldados israelenses não entram em suas casas, sua vigilância está constantemente presente e a sensação de que alguém está te observando dentro da própria casa é uma constante, além de que sempre existe a possibilidade da vigilância se transformar em violência. ${ }^{64}$

Sob vigilância incessante, a casa deixa de ser um refúgio de privacidade e autonomia, para se tornar um lugar de medo e insegurança. E, segundo as autoras supracitadas, mesmo que as próprias casas não sejam invadidas, as mulheres veem ou ouvem soldados regularmente batendo ou derrubando as portas de seus vizinhos; eventos claramente nocivos à saúde mental, que geram pânico e terror.

Neste processo, há também a destruição de pertences pessoais, que para além de objetos materiais, são repositórios vitais de história, significado e identidade, e sua perda é profundamente sentida $^{65}$, de modo que a destruição violenta de objetos pessoais, que evocam memórias e simbologias afetivas, geram dores profundamente enraizadas com as questões culturais e familiares.

Por seu turno, a situação de hostilidade para com a terra dos palestinos, presente no derramamento de lixo, de água contaminada, de resíduos químicos e agrotóxicos consiste em dupla violência, pois além de ameaçar a fonte principal de subsistência dos palestinos, abala igualmente questões afetivas e de pertencimento à terra, seja enquanto matéria, seja enquanto espaço. ${ }^{66}$

\section{Resistências e resiliências}

Estudos relatam que as mulheres palestinas declaram não ter o poder de "proteger" seus filhos e outros membros da família da violência colonial, mas a despeito de toda vulnerabilidade, elas buscam proporcionar todo o conforto possível a seus filhos, parentes e à comunidade mais próxima, tornando a casa um espaço de refúgio e de resistência, como demonstram nestas falas: "Eles querem

\footnotetext{
63 Glenn Albrecht, "The Age of Solastalgia"

${ }^{64}$ Cindy A. Sousa, Susan Kemp, and Mona El-Zuhairi. "Dwelling within political"

${ }^{65}$ Carroll et al., "Flooded homes"

${ }^{66}$ Cindy A. Sousa, Susan Kemp, and Mona El-Zuhairi. "Dwelling within political"
} 
nos matar de fome, mas nós encontraremos uma maneira de nos alimentarmos."; "Quanto mais nos desafiam, mais nos tornamos resilientes e fortes a eles". ${ }^{67}$

Nesta linha de resistência e de resiliência, as mulheres se reapropriam de suas moradias para fins alimentares, econômicos e do cuidar; assim como fazem reivindicações individuais e coletivas de moradia para sua defesa física e simbólica e de sua família. Consoante Scott $(1985)^{68}$, muitos desses "atos diários de resistência" são centrados na comida. Como uma mulher declarou a respeito do uso de sua casa em benefício da comunidade: "Em nossa casa, preparamos diferentes refeições para distribuir." E nesta outra fala: "Eles vão tentar não deixar você trabalhar, então você tem que encontrar alguma maneira de trabalhar e de conseguir dinheiro e comida." Outras descreveram como persistiram na coleta de plantas nativas ou na criação de galinhas e ovelhas para alimentar suas famílias. ${ }^{69}$

Outro exemplo é de uma mulher que iniciou um jardim de infância em sua casa para ajudar a sustentar a família quando o marido perdeu o emprego. Enfatizando o cultural, outras mulheres fabricavam e vendiam produtos tradicionais, como o za'atar (mistura de tomilho, gergelim e sumagre - tempero vermelho) que talvez seja a principal especiaria palestina, assim como bordados com desenhos de significado geográfico e histórico.

Outras narrativas trazem a defesa da pátria de forma mais filosófica e emocional, como uma mulher palestina que detalhou seus esforços para dar sentido à experiência vivida para sua filha: "Eu digo a ela que não se preocupe - eu a encorajo e lhe dou esperança. Eu conto a ela: você não fez nada de errado, por que você está com medo? Você não deve ter medo. Você não os ocupou, você não tomou suas terras. Você está em sua própria terra - não se sinta culpada ou com medo". ${ }^{70}$

Ao proferir tais palavras, essa mãe ensina a filha sobre o orgulho e o direito ao lar, um ato que visa salvaguardar um futuro onde persistirão a família e o povo. A eloquência e defesa do direito de estar em casa configuram, portanto, uma estratégia ao mesmo tempo prática e emocional, individual e coletiva, contrariando os efeitos materiais da ocupação. ${ }^{71}$

Neste sentido, as narrativas de luta dentro de casa geralmente invocam a noção de estar lutando não apenas pela própria família, mas também pelo bem-estar coletivo. Aqui, nossas descobertas são consistentes com um tema emergente em outras pesquisas sobre violência na

\footnotetext{
67 Ibid.

${ }^{68}$ Scott, Weapons of the Weak

69 Cindy A. Sousa, Susan Kemp, and Mona El-Zuhairi. "Dwelling within political"

70 Ibid.

${ }^{71}$ Ibid.
} 
Palestina - sumud ou constância: atos diários contínuos de resistência (micro e macro) destinada a proteger a sobrevivência da terra palestina, a identidade, a dignidade e o bem-estar em face da ocupação. $^{72}$

Seja diretamente, nos confrontos com soldados durante invasões domiciliares, e indiretamente, quando buscam assegurar aos filhos o direito de estar no lugar sem vergonha ou medo, as mulheres usavam a casa para literalmente se manter firme, ecoando a noção de Lefebvre $(1991)^{73}$ de apropriação - o direito humano de fazer, habitar e determinar um espaço.

Segundo Anderson e Danis, (2006) ${ }^{74}$, apesar de qualquer suposição ou garantia de sucesso, as constantes tentativas dos sujeitos para manter certo poder e controle dentro de um contexto de violência, e a resistência estratégica à oposição aberta e direta, constituem estratégias adaptativas que, em última análise, nutrem e sustentam a resiliência.

Os resultados destes estudos acentuam a importância de políticas destinadas a proteger o direito humano universal a uma casa segura e estável ${ }^{75}$, particularmente, em tempos de guerra e conflito, embora não apenas.

De todo modo, a literatura ainda é muito escassa sobre como a violência política afeta a maternidade ${ }^{76}$, como as mães planejam estratégias para manter a si e a seus filhos seguros ${ }^{77}$, e as implicações desse processo para a saúde mental de tais mães. ${ }^{78}$

\section{Considerações finais}

A partir das pesquisas encontradas, fica evidenciado o protagonismo feminino ao longo da história moderna e contemporânea da Palestina. Essa presença, não obstante, como não raro ocorre em outras lutas anticoloniais, tem sido marginalizada ou mesmo invisibilizada ao longo do tempo. Essa omissão encontra suas bases na opressão sexista e, em última análise, contribui com a colonização sionista, no sentido de que mantém concepções e estereótipos orientalistas, colonialistas e eurocêntricos utilizados para a contínua ocupação de terras palestinas, que já perdura 73 anos (19482021).

\footnotetext{
72 Giacaman et al., "Quality of life"

${ }^{73}$ Lefebvre, The Production of Space.

74 Anderson and Danis, "Adult daughters"

75 Young, "House and home"

${ }^{76}$ Levendosky, "Mothers' perceptions of the impact of woman abuse on their parenting". Violence Against Women v. 6 , n. 3, (2000)

${ }^{77}$ Olsen et al., "An ethnography of low-income"

${ }^{78}$ Berman et al., "A narrative study of refugee women"
} 
Sendo assim, se de um modo geral, ainda existe um significativo desconhecimento e consequentes equívocos em relação à questão Palestina e seu povo, permeados por distorções que atendem a interesses de dominação imperialista, a ausência e silenciamento das mulheres palestinas nas páginas que narram a história de uma das maiores injustiças mundiais da era contemporânea aprofunda esse processo e é fundamental para sua manutenção.

Revelar, mesmo que brevemente, esse protagonismo histórico nos marcos da colonização sionista, como se apresenta na primeira parte deste artigo, é ao mesmo tempo uma busca por jogar luz sobre a questão palestina e atuar na lógica de um conhecimento que se pretende transformador da realidade. Visa, nessa direção, contribuir para que mais estudos e pesquisas sejam feitos sobre as mulheres palestinas, preenchendo esta lacuna acadêmica e historiográfica fundamental.

Esse protagonismo feminino, como se observa em outros processos de colonização ao longo da história humana, tem como característica a consciência de que a emancipação das mulheres é inseparável da libertação nacional. Nesse sentido, as mulheres palestinas não travam uma luta isolada contra a opressão, mas sua resistência alcança a interseccionalidade indispensável rumo à libertação plena. E mais: compreende e evidencia que a opressão sexista serve como instrumento à colonização. Como jovens meninas na vanguarda do movimento feminista palestina atual tem se apresentado, herdeiras de uma longa tradição revolucionária de mulheres de sua terra, seu "feminismo vai além das demandas baseadas no gênero individual, instando-nos a lutar por um mundo mais justo e equitativo para todos e todas. ${ }^{79}$

Por sua vez, os estudos desenvolvidos a respeito dos impactos psíquicos da violência de gênero contra mulheres palestinas, seja esta colonial e/ou patriarcal, nos oferece um breve panorama deste contexto todavia pouco conhecido e debatido pela academia brasileira tanto no âmbito das ciências humanas, sociais e da saúde de modo geral, quanto no âmbito da ciência psicológica de modo específico. Em razão desta conjuntura de "ausência", temos como projeto acadêmico futuro trazer a Palestina para a Psicologia brasileira, seja esta social, política e da saúde, haja vista esta problemática carência teórica de tema tão relevante, mas historicamente marginalizado em nosso país, onde estão presentes cerca de 50.000 palestinos e palestinas entre imigrantes, refugiados e descendentes, aqui presentes desde o fim do século XIX.

Conhecer e apreender os sofrimentos e adoecimentos psíquicos em contextos de colonialismo, ocupação e genocídio (também presentes no Brasil com povos originários indígenas e negros) é de fundamental importância para compreendermos as causas sociais e políticas desses processos

\footnotetext{
${ }^{79}$ Marshood and Alsanah. "Tal'at:"
} 
psicopatológicos, de modo a buscar as transformações de uma sociedade adoecida pela violência, quando não basta combater esta última de forma individualizada.

Medidas de curto prazo e de nível micro como programas de atendimento psicológico, melhoria da renda, cooperativas etc., até soluções de médio e longo prazo voltadas para o contexto mais amplo de recuo da ocupação sionista, de fim da violência e do terrorismo de estado israelenses, assim como, cumprimento das resoluções da ONU, das Convenções de Genebra e seus protocolos adicionais do Direito Internacional Humanitário (DHI) devem caminhar juntas para que a paz na Palestina seja efetivamente alcançada e para que esta "terra santa" não seja mais lembrada como território de guerra e conflito.

\section{Referências}

Abdelaziz M. Thabet, Ahmad Abu Tawahina, Eyad El Sarraj. Effect of Domestic Violence on Palestinian Women Mental Health: Pilot study. (2007), https://www.academia.edu/7141626/Effect_of_Domestic_Violence_on_Palestinian_Women_Menta 1_Health_Pilot_study

Abdulhadi, Faiha. The Political Role of Palestinian Woman in the 1930s. Translated from the Arabic Language by Nitham Sais. Ramallah: The Palestinian Women's Research \& Documentation Center, 2015,32 .

Akesson, B. "Castle and cage: meanings of home for Palestinian children and families”. Global Soc. Welf. 1, (2014): 81-95.

Albrecht, G. "The Age of Solastalgia". The Conversation. 7 august 2012. http://theconversation.com/the-age-of-solastalgia-8337.

Amnesty International (2018). Amnesty International Report 2017/2018: The state of the world's human rights.

Amnesty International. 2018. Amnesty International Report 2017/2018: The state of the world's human rights. Retrieved from https://www.amnesty.org/download/Documents/POL1067002018ENGLISH.PDF.

Anderson, K., Danis, F., "Adult daughters of battered women: resistance and resilience in the face of danger." Affilia 21, no. 4, (2006): 419-432.

Antonovsky, A., Unraveling the Mystery of Health: How People Manage Stress and Stay Well. Jossey-Bass, San Francisco, 1987.

Barber, B. K., Spellings, C., McNeely, C., Page, P. D., Giacaman, R., Arafat, C., Mallouh, M. A. "Politics drives human functioning, dignity, and quality of life." Social Science and Medicine 122, (2014): 90-102. 
Berman, H., Giron, E.R.I., Marroquin, A.P., "A narrative study of refugee women who have experienced violence in the context of war." Can. J. Nurs. Res. 41, no. 1, (2009): 144-165.

Brickell, K. Geopolitics of home. Geogr. Compass 6, no. 10, (2012): 575-588.

Bseiso, R. A., and Thabet, A. M. "The relationship between siege stressors, anxiety, and depression among patients with cancer in Gaza Strip." Health Science Journal, 11 no. 2 (2017): 499.

Bulhan, H. A. Frantz Fanon and the psychology of oppression. London, UK: Plenum Press, 1985.

Carroll, B., Morbey, H., Balogh, R., Araoz, G."Flooded homes, broken bonds, the meaning of home, psychological processes and their impact on psychological health in a disaster." Health Place 15, no. 2, (2009): 540-547.

Falah, G.-W. "War, peace and land seizure in Palestine's border area." Third World Q. 25 no. 5, (2004): 955-975.

Fleischmann, Ellen. "The Emergence of the Palestinian Women's Movement, 1929-39", Journal of Palestine Studies, (April 2000): 20-21.

Fleming, J., Mullen, P., Sibthorpe, B., \& Bammer, G. The long-term impact of childhood sexual abuse in Australian women. Child Abuse \& Neglect 23, (1999): 145-159.

Giacaman, R., Abu-Rmeileh, N. M. E., Husseini, A., Saab, H., \& Boyce, W. . "Humiliation: The invisible trauma of war for Palestinian youth. Public Health", 121, no. 8, (2007a): 563-571.

Giacaman, R., Mataria, A., Nguyen-Gillham, V., Abu Safieh, R., Stefanini, A., \& Chatterji, S. "Quality of life in the Palestinian context: An inquiry in war-like conditions". Health Policy, 81, no. 1, (2007b): 68-84.

Giddens, A., The Consequences of Modernity. Stanford University Press, Stanford, CA 1990.

Hamad, B. A., \& Pavanello, S. Transforming cash transfers: Beneficiary and community perspectives on the Palestinian national cash transfer programme part 1: The case of the Gaza Strip. (2012). https://www.odi.org/ sites/odi.org.uk/files/odi-assets/publications-opinion-files/8180.pdf

Hammad, Jeyda and Tribe, Rachel. "Social suffering and the psychological impact of structural violence and economic oppression in an ongoing conflict setting: The Gaza Strip". Journal of Community Psychology. 48 (6) (12 May 2020), https://doi.org/10.1002/jcop.22367

Hanafi, S., "Spacio-cide: colonial politics, invisibility and rezoning in Palestinian territory." Contemp. Arab Aff. 2, no. 1, (2009): 106-121.

Herzl, Theodor. O Estado judeu. Translated by David José Pérez. Rio de Janeiro: Garamond, 1998.

Hind al-Husseini - Personal Info. Visit Palestine. Accessed 25 October 2021. http://visitpalestine.ps/palestinian-personalities/hind-al-husseini/. 
Kagan, C., Burton, M., Duckett, P., Lawthom, R., \& Siddiquee, A. Critical community psychology. West Sussex, England: Wiley-Blackwell, 2011.

Kanafani, Ghassan. A revolta de 1936-1939 na Palestina. Translated by Guilherme Rodrigues e Fabio Bosco. São Paulo: Editora Sundermann, 2015.

Kearns, A., Hiscock, R., Ellaway, A., Macintyre, S., “'Beyond four walls'. The psycho-social benefits of home: evidence from West Central Scotland." Housing Stud. 15 no. 3, (2000): 387-410.

Khalidi, Rashid. The Hundred Years' War on Palestine: A History of Settler Colonial Conquest and Resistance. New York: Metropolitan Books, 2020.

Lefebvre, H. The Production of Space. Blackwell, Cambridge, MA, 1991.

Levendosky, A.A. Mothers' perceptions of the impact of woman abuse on their parenting. Violence Against Women 6, no. 3, (2000): 347-271.

Marshood and Alsanah. "Tal'at: a feminist movement that is redefining liberation and reimagining Palestine." Europe Solidaire Sans Frontières. 25 February 2020. http://www.europesolidaire.org/spip.php?article52242.

Martín-Baró, I. Writings for a liberation psychology. Cambridge, MA: Harvard University Press, 1994.

Massey, D.B. Space, Place, and Gender. University of Minnesota Press, Minneapolis, MN, 1994.

Mataria, A., Giacaman, R., Stefanini, A., Naidoo, N., Kowal, P., \& Chatterji, S. (2009). The quality of life of Palestinians living in chronic conflict: Assessment and determinants. European Journal Health Economics, 10(1), 93-101.

Mervat Sadiq. "The Palestinian "Chysantemun"... A secret feminist organization before the Nakba", Al Jazeera, 15 May 2021.

Misleh, Soraya. "Al Nakba - Um estudo sobre a catástrofe palestina". São Paulo: Editora Sundermann, 2017.

Misleh, Soraya. "Palestina livre, mulheres livres". Monitor do Oriente. https://www.monitordooriente.com/20200307-palestina-livre-mulheres-livres/

Mogannam, Matiel. The Arab Women and The Palestine Problem. London: Herbert Joseph Ltd, 1937.

Olsen, L., Bottorff, J.L., Raina, P., Frankish, C.J., "An ethnography of low-income mothers' safeguarding efforts." J. Saf. Res. 39, no. 6, (2008): 609-616. 
Padgett, D., “There's no place like (a) home: ontological security among persons with serious mental illness in the United States." Soc. Sci. Med. 64, (2007): 1925-1936.

PLO Unified Information. 1979. Foreign Information Department. Palestinian Political Prisoners: Struggle Behind Iron Bars, Beirute, 71-81.

Said, Edward. Orientalismo: O Oriente como invenção do Ocidente. Translated by Rosaura Eichenberg. São Paulo: Companhia das Letras, 2007.

Samaroo, Dima. "The Political Participation of Palestinian Women in Official and Non-Official Organizations in Limited Horizon", Kings' College London, Department of War Studies, International Centre for the Study of Radicalisation, 2018, 10, https://icsr.info/wpcontent/uploads/2018/12/KPMED-Paper_The-Political-Participation-of-Palestinian-Women-in-

Official-and-Non-Official-Organizations-in-Limited-Horizon-1.pdf.

Scott, J. C. Weapons of the Weak: Everyday Forms of Peasant Resistance. Yale University Press, New Haven, 1985.

Seamon, D. A Geography of the Life-world: Movement, Rest and Encounter. St. Martin's Press, London, 1979.

Shalhoub-Kevorkian, Nadera, Ihmoud, Sarah and Dahir-Nashif, Suhad. "Sexual Violence, Women's Bodies, and Israeli Settler Colonialism." Jadaliyya. 17 November 2014. https://www.jadaliyya.com/Details/31481/Sexual-Violence,-Women\%E2\%80\%99s-Bodies,-andIsraeli-Settler-Colonialism.

Smith, Andrea. "Not an indian tradition: the sexual colonization of native peoples". Hypatia: Indigenous Women in the Americas. 18 (2) (2003).

Sousa, Cindy A., Kemp, Susan and El-Zuhairi, Mona. "Dwelling within political violence: Palestinian women's narratives of home, mental health, and resilience." Health \& Place 30 (2014): 205-214.

Thabet, A. A., and Thabet, S. "Stress, trauma, psychological problems, quality of life and resilience of Palestinian families in the Gaza Strip." Journal of Clinical Psychiatry, n 2, (2015): 1-16.

UN. Resolução 181, de 29 de novembro de 1947, da Assembleia Geral das Nações Unidas, 1947, https://unispal.un.org/dpa/dpr/unispal.nsf/0/7f0af2bd897689b785256c330061d253.

Wadi, Shahd. "Feminismos de corpos ocupados: as mulheres palestinianas entre duas resistências", PhD diss., University of Coimbra, 2009.

Ward, A. "Women of the Lebanese mountains: a fight for edification." Womens Stud. Int. Forum 32, no. 5, (2009): 388-394.

Young, I. M. "House and home: feminist variations on a theme." In: On Female Body Experience: "Throwing Like a Girl" and Other Essays, Young, I.M. ed.. Oxford University Press, New York, NY, 2005. 